\title{
CINETICA DE LA SUSCEPTIBILIDAD ANTIMICROBIANA DE LA Escherichia coli FRENTE A LA NITROFURANTÍNA
}

\author{
Almeida Pacasi, Sandra ${ }^{1}$ \\ Fernández Sánchez, Harley ${ }^{1}$ \\ Sato Soto, Fernando ${ }^{1}$ \\ Victorio Gonzales, Denisse ${ }^{1}$ \\ Padilla Lauriano, Josué ${ }^{2}$
}

\section{RESUMEN}

El presente trabajo expone ¿En qué concentración de Nitrofurantoína la Escherichia coli presenta susceptibilidad antimicrobiana? Para lo cual se utilizó el método de determinación de susceptibilidad antimicrobiana "macro dilución en caldo".

El objetivo principal de este trabajo fue obtener la concentración de Nitrofurantoína en la que la bacteria Escherichiacoli presenta susceptibilidad antimicrobiana, para esto se determinó la concentración mínima inhibitoria de la Nitrofurantoína para el crecimiento de colonias de Escherichiacoli, y el tiempo de acción de la Nitrofurantoína para inducir la muerte de dicha bacteria.

Encontrándose que a concentraciones mayores del $75 \%$ el crecimiento de las colonias queda inhibido y después de 4 horas de someter las colonias con nitrofurantoina se le ocasiona la muerte.

Esto nos indica que existe una concentración optima para controlar el crecimiento de las colonias, siempre en cuando esta sea controlada en el tiempo. Por lo que podemos atrevernos a plantear que con un menor número de colonias el control puede ser mas eficiente.

Palabras claves: Escherichia coli, Susceptibilidad, Nitrofurantoina

Laboratorio de Química de la Facultad de Ciencias Biológicas, Universidad Ricardo Palma.

Docente de Fisicoquímica de la Facultad de Ciencias Biológicas, Universidad Ricardo Palma; e-mail: abw.padillal@urp.com 


\section{SUMMARY}

The research presents what concentrations of Nitrofurantoin in the bacteria Escherichia coli presents antimicrobial susceptibility. Therefore, it was used the macrodilution method in liquid culture medium to determine antimicrobial susceptibility.

The research had the main objective to find out the concentration of Nitrofurantoin (aqueous solution) in which the E. Coli presents antimicrobial susceptibility. For that, it was determined the inhibiting minimum concentration of Nitrofurantoin for the E. Coli colonies growth, also the time Nitrofurantoin needs to induce the death of this bacterium.

Finally, it was obtain that concentrations above the $75 \%$ of Nitrofurantoin are able to inhibit the growth of colonies and that 4 hours of exposure of this antibiotic to the bacteria is enough to kill them.

This proves that there is an optimal concentration for controlling the growth of E. Coli colonies, as long as the time is controlled as well. For all previously mentioned, it is precise to propose that with a lower number of $\mathrm{E}$. Coli colonies the control can become more efficient.

Keywords: Escherichia coli, Susceptibility, Nitrofurantoin.

\section{INTRODUCCIÓN}

La cuantificación de la actividad in vitro de los antimicrobianos se evalúa habitualmente mediante alguna de las variantes de los métodos de dilución. Estos métodos se basan en la determinación del crecimiento del microorganismo en presencia de concentraciones crecientes del antimicrobiano, que se encuentra diluido en el medio de cultivo (caldo o agar).

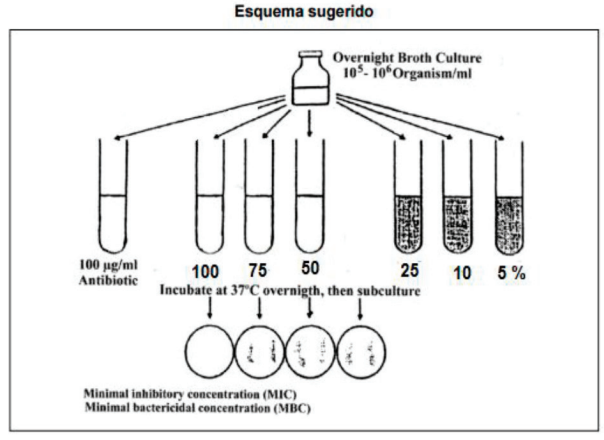

Concentración mínima inhibitoria (CMI)

Es la mínima concentración de antibiótico que en un periodo de tiempo predeterminado, es capaz de inhibir el crecimiento de un inoculo bacteriano previamente estandarizado (concentración conocida de gérmenes). 


\section{Concentración mínima bactericida (CMB)}

Es la mínima concentración de un antibiótico que en un periodo de tiempo predeterminado, es capaz de inducir la muerte in vitro del $99.9 \%$ de una población bacteriana previamente estandarizada.

\section{Escherichia coli}

La bacteria de la especie Escherichia coli son bacilos Gram negativos, quimioheterotrofos, catalasa positiva, oxidasa negativa, anaerobios facultativos.

Las cepas de E. coli se pueden diferencia una de otras, teniendo como base sus antígenos somáticos $(\mathrm{O})$, flagelares $(\mathrm{H})$ y capsulares $(\mathrm{K})$.

La mayoría de las cepas pertenecientes a la especie Escherichia coli, forman parte de la microflora normal del intestino del hombre y de los animales de sangre caliente, encontrándose habitualmente en las heces.

\section{Nitrofurantoína}

Es un nitrofurano antibacteriano que se utiliza específicamente para el tratamiento de bacterias gram negativas. La nitrofurantoina inhibe la acetilcoenzima A bacteriana, interfiriendo con el metabolismo de los carbohidratos e impidiendo la formación de la pared celular.

En general es bacteriostática, pero a altas concentraciones puede ser bactericida frente a determinados microorganismos como la E. coli. Se consideran susceptibles a la nitrofurantoina aquellos gérmenes que son inhibidos por concentraciones de hasta $25 \mathrm{ug} / \mathrm{ml}$, mientras que son considerados como resistentes aquellos que requieran concentraciones de 100 up/ml a mas.

\section{PROCEDIMIENTO}

\section{PREPARACION DEL MEDIO DE CULTIVO:}

- En un frasco de vidrio llenar $500 \mathrm{ml}$ de agua destilada

- Pesar 10 gr de agar de Muller Hinton x $250 \mathrm{ml}$ de agua destilada

- Agregar el agar al agua destilada y homogenizar

- Esterilizar en autoclave, y luego esperar que enfrie.

- Ponga el medio de cultivo en las placas Petri hasta un nivel aproxi- 
mado de $4 \mathrm{~mm}$. Esto corresponde $10 \mathrm{ml}$ por placa aproximadamente.

- Controlar la esterilidad de cada lote incubando 24 horas o más a $30-35^{\circ} \mathrm{C}$.

\section{PREPARACION DEL CALDO NUTRITIVO (AGUA PEPTONADA):}

- Medir $400 \mathrm{ml}$ de agua destilada

- Pesar 7.6 gr de agua peptonada x $200 \mathrm{ml}$ de agua destilada

- Agregar lo pesado en un frasco y homogeneizar

- Esterilizar en autoclave, y luego dejar enfriar.

PREPARACION DEL ANTIBIOTICO (NITROFURANTOINA):

- Usar frasco esterilizado para la preparación del antibiótico.

- Medir $50 \mathrm{ml}$ de solución salina y vaciar al frasco estéril.

- Agregar 500 mg de antibiótico (100gr por cada capsula) y homogeneizar

ACTIVACION DE LA BACTERIA:

- En un tubo de ensayo echar $10 \mathrm{ml}$ del caldo nutritivo

- Agregar 1 colonia de la cepa de E. coli

- Llevar a incubar por 24 horas o más a $30-35^{\circ} \mathrm{C}$ en la estufa

\section{DILUCION DEL ANTIBIOTICO}

- En 4 tubos de ensayo estériles se debe colocar $0 \mathrm{ml}, 2.5 \mathrm{ml}, 5 \mathrm{ml}$ y $7.5 \mathrm{ml}$ de agua peptonada.

- Luego se le debe adicionar $100 \mathrm{ml}$ (100\%), $7.5 \mathrm{ml}$ (75\%), $5 \mathrm{ml}$ $(50 \%)$ y $2.5 \mathrm{ml}(25 \%)$ del antibiótico a los tubos respectivamente, de tal manera que en los 4 tubos haya un volumen de $10 \mathrm{ml}$.

- Finalmente se debe adicionar $50 \mathrm{uL}$. de la bacteria activada, previamente incubada.

SIEMBRA DE BACTERIA

- La siembra se realizara en un lapso de 4 horas, sembrando 1 placa por hora, estas con las siguientes concentraciones $100 \%, 75 \%, 50 \%$ y $25 \%$ 
- Usar un aza de siembra con 0.5 um de diámetro para el aro.

- Sumergir el aro de la aza al primer tubo $100 \%$ y realizar un barrido en la superficie del agar Muller Hinton en placa petri. Repetir esta acción para la primera hora en las concentraciones restantes.

- Cada vez que se repite el proceso se debe esterilizar el aza.

- Una vez terminada la acción para la primera hora llevar las placas a la estufa a incubar, y así se debe realizar con los siguientes tiempos.

- Dejar incubar las placas por 24 horas aprox.

\section{RESULTADOS}

Número de colonias de e. coli a diferentes concentraciones de antibiotico en diferentes tiempos.

\begin{tabular}{|c|c|c|c|c|}
\hline $\begin{array}{c}\text { Concentración / } \\
\text { Tiempo (hrs) }\end{array}$ & $\begin{array}{c}\text { Nitrofurantoína } \\
\text { al } 25 \%\end{array}$ & $\begin{array}{c}\text { Nitrofurantoína } \\
\text { al } 50 \%\end{array}$ & $\begin{array}{c}\text { Nitrofurantoí- } \\
\text { na al } 75 \%\end{array}$ & $\begin{array}{c}\text { Nitrofurantoína } \\
\text { al } 100 \%\end{array}$ \\
\hline 1 & 47 & 36 & 90 & 65 \\
\hline 2 & 52 & 45 & 84 & 60 \\
\hline 3 & 59 & 53 & 70 & 45 \\
\hline 4 & $>1600$ & $>1600$ & 64 & 30 \\
\hline
\end{tabular}
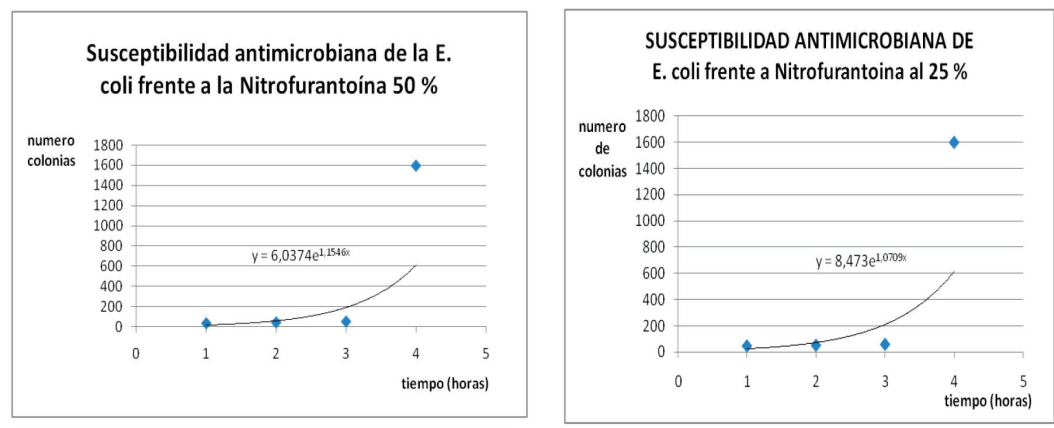

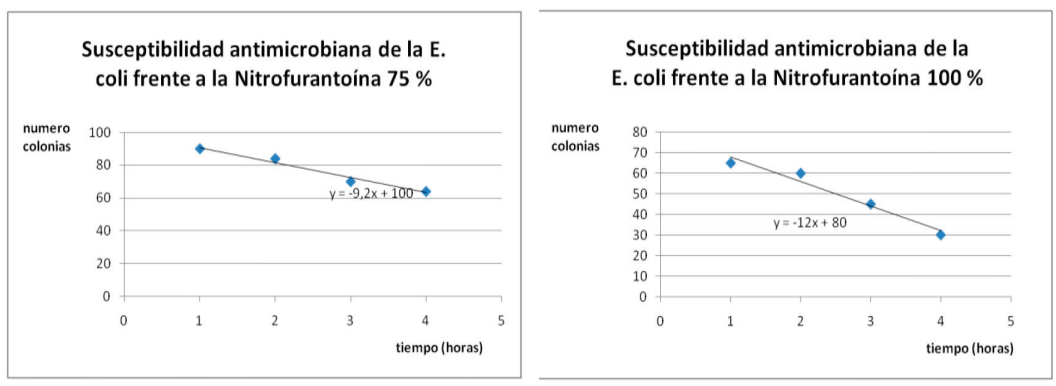

\section{DISCUSIÓN}

se puede deducir que solo las concentraciones de nitrofurantoina al 75 y $100 \%$ actúan como un catalizador negativo (inhibe el crecimiento de colonias de la bacteria Escherichia coli) hasta las 4 horas experimentales ya que estas presentan 64 y 30 colonias respectivamente. Al comparar estas con el numero de colonias de la nitrofurantoina al 25 y $50 \%$ que sobrepasan las 1600 colonias, se concluye que se logra cumplir la hipótesis en donde se expone que a mayor concentración de Nitrofurantoína en un determinado tiempo es menor la cantidad de colonias de la bacteria Escherichia coli.

\section{CONCLUSIONES}

A menor concentración de Nitrofurantoína, menor es su tiempo de acción como bactericida. Porque al analizar la concentración de nitrofurantoina al $25 \%$ se observa que el numero de colonias a la primera hora es de 47 , numero mayor que el de la CMI que es de 36 colonias, entonces se concluye que el antibiótico en esta concentración no actúa como bactericida ya que se observa también que a las siguientes horas va aumentando el número de colonias en vez de disminuir. 


\section{REFERENCIAS BIBLIOGRÁFICAS}

BARRY, R.;1976 Inhibition of bacterial growth by the nitrofurantoin solvent dimethylformamide. antimicrobial agents and chemotherapy. vol. 9 , no. $3: 549-550$

Díaz L.; Cabrera L.; Fernández T.; González O.; Carrasco O. y Bravo L.;2006; Etiología bacteriana de la infección urinaria y susceptibilidad antimicrobiana en cepas de Escherichiacoli. Rev. Cubana Pediatra v.78 n.3 Ciudad de la Habana .

Goldraich N, Manfroi A.;2002 Febrileurinarytractinfection: Escherichiacolisusceptibilityto oral antimicrobials. PediatrNephrol.; 17(3):173-6 